\title{
Improving the relaxing effect of terbutaline with phosphodiesterase inhibitors: Studies on pregnant rat uteri in vitro
}

\author{
Anna Klukovits, Judit Verli, George Falkay, Róbert Gáspár* \\ Department of Pharmacodynamics and Biopharmacy, University of Szeged, H-6720 Szeged, Eötvös u. 6., Hungary
}

\section{A R T I C L E I N F O}

\section{Article history:}

Received 24 June 2010

Accepted 8 October 2010

\section{Keywords:}

$\beta_{2}$-adrenergic receptor agonist

Phosphodiesterase 4 inhibitor

Genital inflammation

Preterm labor

\begin{abstract}
A B S T R A C T
Aims: Previous results by our group showed that the in vitro uterus-relaxing potency of $\beta_{2}$-adrenergic receptor $\left(\beta_{2}-A R\right)$ agonists and uterine cAMP accumulation are enhanced in case of visceral inflammation. Our aim was to study the effects of the non-selective phosphodiesterase (PDE) inhibitor theophylline and the selective PDE4 inhibitor rolipram on the uteri of intact late-pregnant female rats (on days 20 and 22 of pregnancy) and of pregnant rats treated with lipopolysaccharide (LPS) to evoke preterm labor (on day 20). Main methods: The effects of theophylline and rolipram alone and of rolipram with terbutaline were investigated in isolated organ system. Contractions were evoked with $\mathrm{KCl}$. The forskolin- and terbutalinestimulated cAMP accumulations were determined by enzyme immunoassay, with or without rolipram. Key findings: The maximum uterus-relaxing effects of theophylline and rolipram decreased significantly $(p<0.05)$ with the progression of pregnancy in intact rats. The most pronounced effect of rolipram was detected in rats challenged with LPS on day 20. Rolipram increased the in vitro effect of terbutaline both in intact and in LPS-treated rats. In the presence of rolipram, the forskolin- and terbutaline-stimulated cAMP accumulations were higher in LPS-treated than in intact rats.

Significance: The previous findings led us to conclude that the combined administration of PDE4 inhibitors with $\beta_{2}$-agonists is of therapeutic value for the inhibition for uterine contractions, especially in the case of genital inflammation, which often triggers preterm birth. Combination therapy in general is associated with lesser side-effects, as a consequence of lower effective doses of each drug.
\end{abstract}

(C) 2010 Elsevier Inc. All rights reserved.

\section{Introduction}

Preterm uterine contractions can develop as a result of several pathological processes, among which intrauterine infection plays a key role (Romero et al., 1988). The inflammatory processes trigger a wide range of uterus-contracting factors, which eventually lead to the development of uterine contractions (Lindström and Bennett, 2005). At the same time, the contractions in the pregnant myometrium are counterbalanced in part by cyclic adenosine-monophosphate (cAMP)-dependent relaxation mechanisms. A plethora of ligands such as $\beta_{2}$-adrenergic receptor $\left(\beta_{2}\right.$-AR) agonists can stimulate the generation of cAMP in the myometrium, whereas phosphodiesterase enzymes (PDEs) warrant termination of signalling by the degradation of cAMP to the inactive 5'-AMP (Houslay 2003).

We earlier demonstrated that the in vitro uterus-relaxing potency of the $\beta_{2}$-AR agonist terbutaline is enhanced in pregnant rats challenged with bacterial lipopolysaccharide (LPS) to evoke preterm birth. We also found that, in case of local inflammation, terbutaline has an increased cAMP-accumulating potency, which is probably

\footnotetext{
* Corresponding author. Tel./fax: + 3662545567.

E-mail address: gaspar@pharm.u-szeged.hu (R. Gáspár).
}

mediated by the sensitization of adenylyl cyclase by tumor necrosis factor- $\alpha$ (TNF- $\alpha$ ) (Klukovits et al., 2009). On the other hand, the local PDE activity may as well be an important regulator of cAMPdependent relaxation processes.

The PDE enzymes are encoded by 11 related gene families and are differentially expressed in human tissues (Lugnier, 2006). Human myometrial cells (Méhats et al., 1999), amniochorionic membranes (Oger et al., 2005), monocytes and neutrophils (Wang et al., 1999) express PDE4, which promotes its role in either smooth muscle or immune functions. At present, PDE4 comprises the largest PDE family, constituted by 4 genes with various alternative mRNA splices encoding at least 35 different PDE4 isoenzymes. Rolipram is the archetypal PDE4 inhibitor $\left(K_{\mathrm{i}}=0.8 \mu \mathrm{M}\right)$; and no selective inhibitor is currently available that discriminates PDE4 isoenzymes (Lugnier, 2006).

The aim of the present study was to test the effects of non-selective PDE or selective PDE4 inhibitors alone or in combination with $\beta_{2}$-AR agonists on uterine contractions in vitro. We tested the effects of the non-selective PDE inhibitor theophylline and the specific PDE4 inhibitor rolipram on isolated uterine rings from intact and LPStreated late-pregnant rats. We also investigated the effects of $\beta_{2}$-AR agonist terbutaline with PDE4 blockade in the same experimental model. Uterine cAMP levels were measured by means of enzyme 
immunoassay (EIA) after stimulation with the direct adenylyl cyclase activator forskolin, in the presence of rolipram. The accumulation of cAMP was also detected in the presence of terbutaline and rolipram alone, and their combination.

\section{Methods}

Animals

The animals were treated in accordance with the European Communities Council Directives (86/609/ECC) and the Hungarian Act for the Protection of Animals in Research (XXVIII.tv.32.§). All experiments involving animal subjects were carried out with the approval of the Hungarian Ethical Committee for Animal Research (registration number: IV./01758-2/2008) and under the control of the ISO-9001:2008 Quality Management System.

Sexually mature female Sprague-Dawley rats (body mass: 140-160 g, 50-60 days old) were mated in the early morning hours. Copulation was confirmed by the presence of a copulation plug or spermatozoa in the vagina. The day of copulation was considered to be the first day of pregnancy. The animals were housed in temperature- $\left(20-23{ }^{\circ} \mathrm{C}\right)$, humidity- (40-60\%) and light- (12 h of light, $12 \mathrm{~h}$ of dark) regulated rooms, with water and food intake ad libitum.

\section{In vivo treatments}

The animals were divided into 3 groups $(n=6-8$ in each): (1) intact pregnant rats on day 22 of pregnancy; (2) intact pregnant rats on day 20 of pregnancy; and (3) rats treated with LPS (i.p. $125 \mu \mathrm{g} / \mathrm{day}$ ) in the early morning hours for three consecutive days from day 18 of pregnancy to evoke preterm birth, which occurred during the early afternoon of day 20 (Elovitz and Mrinalini, 2004).

\section{In vitro contractility studies}

On days 20 and 22 of pregnancy the rats were killed by $\mathrm{CO}_{2}$ inhalation in the early afternoon hours, and the uteri were removed and prepared for the in vitro contractility assay, as it was reported previously (Klukovits et al. 2004). Briefly, the isolated uterine horns were immediately placed in an organ bath (de Jongh solution; containing in mM: $137 \mathrm{NaCl}, 3 \mathrm{KCl}, 1$ $\mathrm{CaCl}_{2}, 1 \mathrm{MgCl}_{2}, 12 \mathrm{NaHCO}_{3}, 4 \mathrm{Na}_{2} \mathrm{HPO}_{4}, 6$ glucose; $\mathrm{pH}$ 7.4) perfused with 95\% oxygen and $5 \%$ carbon dioxide; they were trimmed of fat and the foeto-placental units were removed. Temperature was maintained at $37^{\circ} \mathrm{C}$. Four rings $1 \mathrm{~cm}$ long were sliced from the middle part of each horn, including implantation sites, and tested in parallel; they were mounted vertically in the above-mentioned organ bath under the same conditions. After mounting, the initial tension was set at $1.5 \mathrm{~g}$ and the rings were equilibrated for $60 \mathrm{~min}$, with change of the buffer every $15 \mathrm{~min}$. Rhythmic contractions were then elicited with $25 \mathrm{mM} \mathrm{KCl}$. The effects of the non-specific PDE inhibitor theophylline, the specific PDE4 inhibitor rolipram and/or the $\beta_{2}$-AR agonist terbutaline on uterine rings were measured in the concentration range $10^{-12}-10^{-5} \mathrm{M}$, in a cumulative manner. The tissue samples were incubated for $4 \mathrm{~min}$ with each concentration. The tension of the myometrial rings was measured with a strain gauge transducer (SG-02, Experimetria Ltd, Budapest, Hungary), and recorded and analysed with the SPEL Advanced ISOSYS Data Acquisition System (Experimetria Ltd, Budapest, Hungary). Areas under the curves (AUCs) of 4-min periods were evaluated; the effects of rolipram and terbutaline were expressed as percentages of the $\mathrm{KCl}-$ induced contractions preceding the administration of the relaxing drugs. The maximum contraction-inhibiting values were calculated.

\section{Measurement of uterine cAMP accumulation}

Uterine samples from intact 22-day pregnant and LPS-treated 20-day pregnant rats were incubated in de Jongh solution, under the same conditions as detailed above. Forskolin $\left(10^{-8}-10^{-6} \mathrm{M}\right)$-stimulated cAMP accumulation was determined in the presence of the specific PDE4 inhibitor rolipram $\left(10^{-8}\right.$ or $\left.10^{-5} \mathrm{M}\right)$. The extents of cAMP accumulation were also determined in the presence of terbutaline $\left(10^{-7} \mathrm{M}\right)$ or rolipram $\left(10^{-6} \mathrm{M}\right)$ alone, and also in combination. After stimulation, the samples were immediately frozen in liquid nitrogen and stored until the extraction of cAMP (Gaspar et al., 2007). Frozen tissue samples were then ground, weighed, homogenized in 10 volumes of ice-cold 5\% trichloroacetic acid and centrifuged at $1000 \mathrm{~g}$ for $10 \mathrm{~min}$. The supernatants were extracted with 3 volumes of water-saturated diethyl ether. After drying, the extracts were stored at $-70{ }^{\circ} \mathrm{C}$ until the cAMP assay. Uterine cAMP accumulation was measured with a commercial competitive cAMP EIA Kit, tissue cAMP levels were expressed in $\mathrm{pmol} / \mathrm{mg}$ tissue.

\section{Statistical analyses}

All experiments were carried out on at least 6 animals and each value is given as a mean \pm S.E.M. All the data calculations, curve fittings (sigmoidal concentration-response curves), and statistical analyses were performed with the Prism 4.0 computer software (Graph Pad Software Inc, San Diego, CA, USA). Group comparisons were made by one-way ANOVA tests with Newman-Keuls post-test.

\section{Drugs}

Rolipram, theophylline, terbutaline, LPS (E. coli endotoxin 055:B5), 3-isobutyl-1-methylxanthine, forskolin and the cAMP EIA Kit were purchased from Sigma-Aldrich Ltd, Budapest, Hungary.

\section{Results}

In vitro contractility studies

Uterine activity was characterized by the AUCs of $\mathrm{KCl}$-stimulated contractions of uterine rings in vitro. Time control experiments revealed that $\mathrm{KCl}$-stimulated contractions do not decrease significantly through the experiment (40-45 min). Although the non-specific PDE inhibitor theophylline had very limited effect in the uteri of intact rats, it showed significant effect in LPS-treated rats (Fig. 1). In the intact rats, the effect of theophylline varied, depending on the day of pregnancy: the KCl-induced contractions were reduced by theophylline to $47.04 \pm 3.53$ S.E.M.\% on day 20 ( 2 days before physiological term) and to $74.66 \pm 2.46$ S.E.M.\% on day

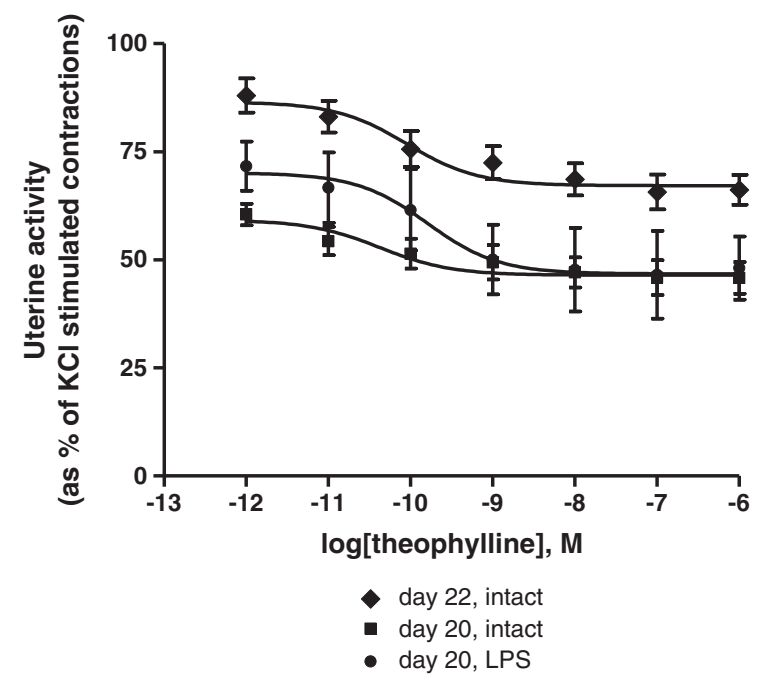

Fig. 1. Effects of theophylline on pregnant uterine contractions in vitro. The contractions were elicited with $25 \mathrm{mM} \mathrm{KCl}$ in uterine rings of intact rats on days 20 (一) and $22(\bullet)$ of pregnancy, and in LPS-treated rats on day $20(\bullet)$ of pregnancy. $n=8$ in each group. 
22 (at physiological term) $(p<0.001)$. In the group of rats treated with LPS, which delivered on day 20, theophylline decreased the contractions to $54.89 \pm 10.90$ S.E.M.\%, which was not different from that in the intact rats on day $20(p>0.05)$ but was lower than that on day $22(p<0.05)$. The $\mathrm{EC}_{50}$ values of theophylline were not different $(p>0.05)$ in the intact rats either on day $20\left(1.67 \pm 1.11 \times 10^{-9} \mathrm{M}\right)$ or on day $22\left(4.20 \pm 1.81 \times 10^{-8} \mathrm{M}\right)$, or in the LPS-treated rats $\left(3.52 \pm 2.34 \times 10^{-8} \mathrm{M}\right)$.

The contraction-inhibiting effect of the specific PDE4 inhibitor rolipram exhibited a similar tendency: a declining relaxing effect towards term (Fig. 2). In the intact late-pregnant rats, the maximum contractioninhibiting effect was seen on day 20, when the contractions were reduced to $54.85 \pm 4.21$ S.E.M.\%. The effect of rolipram was the weakest on day 22 , when the contractions were reduced to $77.66 \pm 7.13$ S.E.M.\%, resulting in a weaker $(p<0.05)$ inhibition than that on day 20. In the LPS-treated rats, however, the contractions were reduced to $19.1 \pm 4.96$ S.E.M.\%, resulting in a more marked inhibition than that in intact rats on day $20(p<0.01)$. As regards the $\mathrm{EC}_{50}$ values of rolipram, despite the increasing trend in the values towards physiological term, there were no significant differences $(p>0.05)$ between the intact rats and the LPS-treated rats.

The effects of the $\beta_{2}$-AR agonist terbutaline alone or in the presence of rolipram were also tested on the isolated uterine rings. Terbutaline decreased the $\mathrm{KCl}$-stimulated contractions to $39.23 \% \pm 4.14$ S.E.M.\%, on day 22 of pregnancy (Fig. $3 \mathrm{~A}$ ). In the presence of $10^{-6} \mathrm{M}$ rolipram, the contractions were reduced by terbutaline to $25.98 \pm 2.98$ S.E.M.\% $(p<0.05)$. In the LPS-treated rats (Fig. 3B), on day 20 of pregnancy, terbutaline alone decreased the uterine contractions to $35.75 \pm 3.60$ S.E. $\mathrm{M} . \%$, while in the presence of rolipram the $\mathrm{KCl}$-induced contractions were reduced to $9.85 \pm 5.21$ S.E.M.\% $(p<0.01)$.

\section{Uterine cAMP levels}

The effects of the adenylyl cyclase activator forskolin were at first investigated in intact 22-day-pregnant and LPS-treated 20-day-pregnant rats. In the presence of rolipram $\left(10^{-8} \mathrm{M}\right)$, forskolin $\left(10^{-8}-10^{-6} \mathrm{M}\right)$ concentration-dependently increased the uterine cAMP levels in both groups (Fig. 4A). In the uteri of the LPS-treated rats, $10^{-8}, 10^{-7}$ and $10^{-6} \mathrm{M}$ forskolin all evoked higher cAMP accumulation than in intact 22day-pregnant rats $(p<0.001)$. Similarly, when rolipram was present in higher concentration $\left(10^{-5} \mathrm{M}\right)$ (Fig. $4 \mathrm{~B}$ ), $10^{-8}, 10^{-7}$ and $10^{-6} \mathrm{M}$ forskolin stimulation again resulted in significantly higher uterine cAMP concentrations in the LPS-treated than in the intact rats $(p<0.01)$. At $10^{-8}$ and $10^{-7}$ (but not at $10^{-6}$ ) $\mathrm{M}$ forskolin, the uterine cAMP levels were

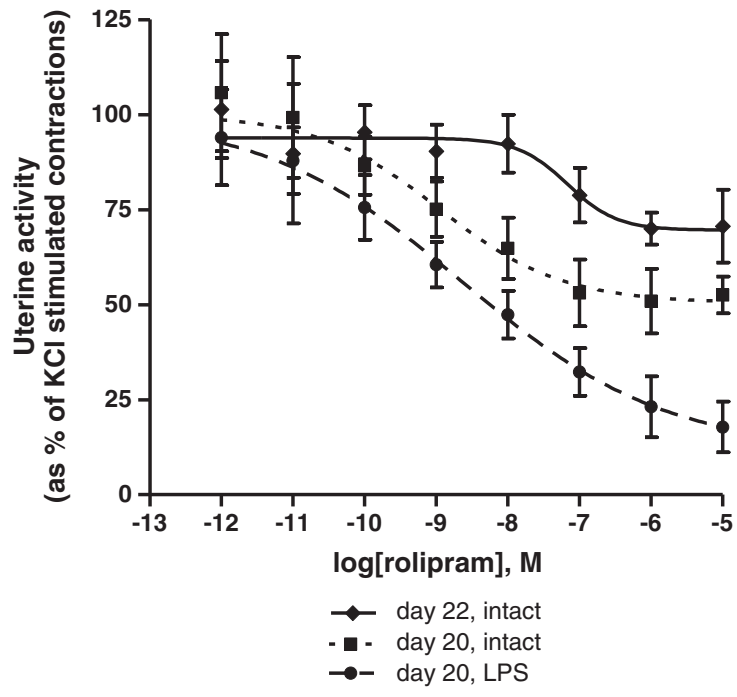

Fig. 2. Effects of rolipram on pregnant uterine contractions in vitro. The contractions were elicited with $25 \mathrm{mM} \mathrm{KCl}$ in uterine rings of intact rats on days $20(\mathbf{\square})$ and $22(\bullet)$ of pregnancy, and in LPS-treated rats on day $20(\bullet)$ of pregnancy. $n=8$ in each group.
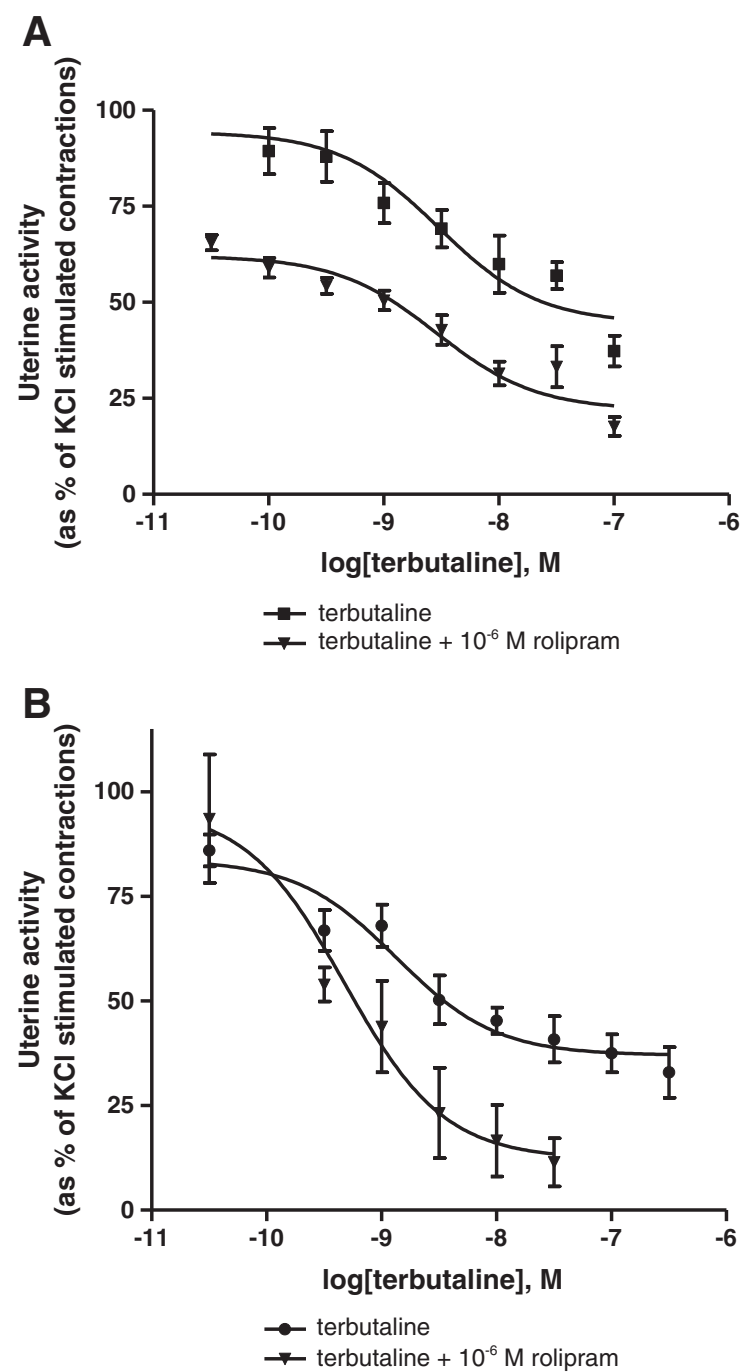

Fig. 3. Effect of rolipram on the uterine-relaxing effect of terbutaline in vitro. The contractions were elicited with $25 \mathrm{mM} \mathrm{KCl}$ in uterine rings of intact rats on day $22(\boldsymbol{\square})$ (Fig. 3A) or of LPS-treated rats on day 20 ( $\mathbf{\nabla}$ ) of pregnancy (Fig. 3B). In the presence of $10^{-6} \mathrm{M}$ rolipram, the maximum contraction-inhibiting effects of terbutaline were lower both in the intact $(p<0.05)$ and in the LPS-treated rats $(p<0.01) . n=8$ in each group.

higher in the presence of $10^{-5} \mathrm{M}$ rolipram than of $10^{-8} \mathrm{M}$ rolipram, in both groups.

The cAMP generation in the pregnant uterus was measured in the presence of terbutaline $\left(10^{-7} \mathrm{M}\right)$ or rolipram $\left(10^{-6} \mathrm{M}\right)$ alone and of their combination (Fig. 5). Both in the intact and in the LPS-treated rats, the cAMP concentrations were significantly higher in the presence of terbutaline + rolipram than with only terbutaline $(p<0.001)$ or rolipram $(p<0.001)$. The combination of terbutaline + rolipram resulted in higher cAMP levels in the LPS-treated rats than in the intact rats $(p<0.01)$.

\section{Discussion}

Most of the interventions intended to reduce preterm birth rate have not achieved consistent benefit. Apart from manifest infections in late-pregnancy, when the termination of pregnancy is of utmost importance to save the mother and the infant, the causes of preterm contractions are seldom recognized before the initiation of tocolytic therapy. The administration of uterorelaxant drugs might provide time for obstetrical interventions such as screening for asymptomatic bacteriuria, antenatal corticosteroid treatment and prophylactic 

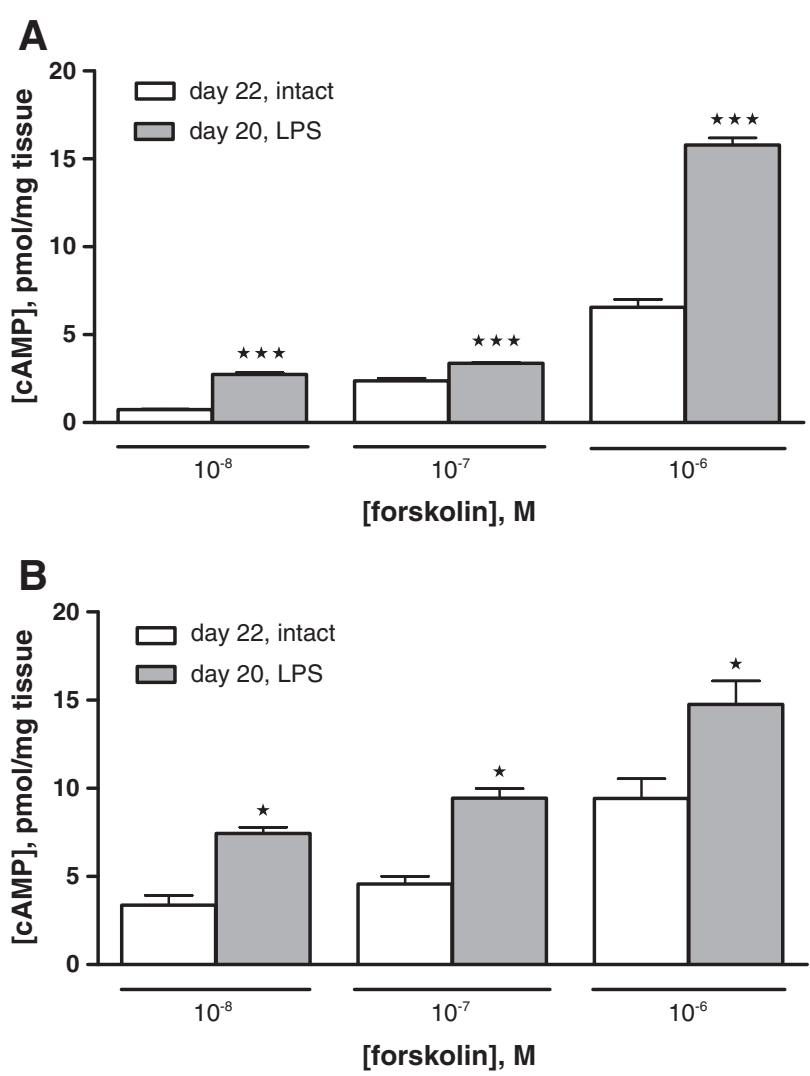

Fig. 4. Intracellular cAMP levels in the pregnant rat uterus, in the presence of forskolin and rolipram. In the presence of $10^{-8} \mathrm{M}$ (Fig. 4A) or $10^{-5} \mathrm{M}$ (Fig. 4B) rolipram, forskolin $\left(10^{-8}-10^{-6} \mathrm{M}\right)$ concentration-dependently increased the uterine cAMP levels in intact rats on day 22 and in LPS-treated rats on day 20. In the uteri of the LPStreated rats, the extent of cAMP accumulation was higher than in those of the intact rats. $n=6$ in each group; ${ }^{* *}: p<0.01 ;{ }^{* * *}: p<0.001$.

antibiotic treatment for group B streptococcal infections (Iams et al., 2008; Withworth and Quenby, 2008). Early intervention, hospitalization of the mother and the initiation of further treatment can increase the survival prospects of infants born preterm.

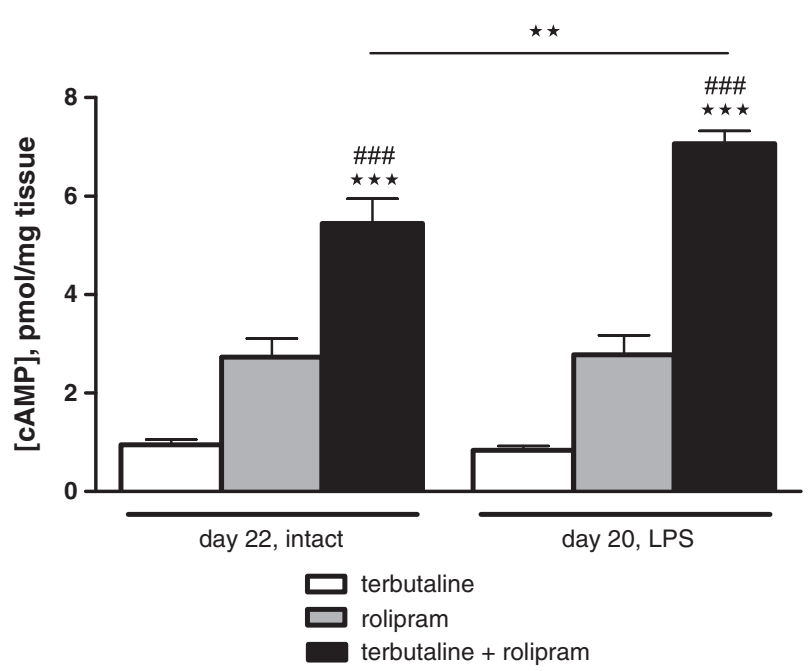

Fig. 5. Intracellular cAMP levels in the pregnant rat uterus, in the presence of terbutaline or rolipram and their combination. Both in the intact and in the LPS-treated rats, the cAMP concentrations were higher in the presence of terbutaline + rolipram than with only terbutaline $\left(10^{-7} \mathrm{M}\right.$; $\left.{ }^{* * *}: p<0.001\right)$ or rolipram $\left(10^{-6} \mathrm{M}\right.$; \#\#\#: $\left.p<0.001\right)$. The combination of terbutaline + rolipram resulted in higher cAMP levels in the LPS-treated rats than in the intact rats $\left({ }^{* *}: p<0.01\right) . n=6$ in each group.
In view of the role of inflammation in the provocation of preterm contractions, it appears advantageous to apply tocolytics with antiinflammatory effects. Both $\beta_{2}$-AR agonists and PDE4 inhibitors were reported to have an anti-inflammatory effect (Chi et al., 2004; Hatzelmann and Schudt, 2001; Farmer and Pugin, 2000; Francischi et al., 2000). In immunocompetent cells, where PDE4 enzymes are abundant, increased cAMP levels lead to inhibition of the synthesis and release of pro-inflammatory mediators, cytokines and active oxygen species. The $\beta_{2}$-AR agonists have immediate and comparable profound effects on uterine activity (de Heus et al., 2008). Despite their unfavorable side-effects (tachycardia and the risk of pulmonary hypertension), the $\beta_{2}$-AR agonists are still irreplaceable in tocolytic therapy. Recent publications have recommended the use of PDE4 inhibitors for tocolysis, but clinical experience was controversial (Méhats et al., 2007). Monotherapy with rolipram or roflumilast was hindered by adverse effects such as unacceptable nausea and vomiting (Dyke and Montana, 2002).

Our study confirmed that the non-selective PDE inhibitor theophylline has only limited uterorelaxant effect in the late-pregnant rat. The selective PDE4 inhibitor rolipram, however, turned out to be much more effective to inhibit the $\mathrm{KCl}$-induced uterine contractions. In the late-pregnant rat uterus the administration of $25 \mathrm{mM} \mathrm{KCl}$ elicits rhythmic, sustainable uterine contractions, which do not decline over an approximately $45 \mathrm{~min}$ period. In this model, we could assess the effects of the PDE inhibitors and of terbutaline in a cumulative manner. In the in vitro contractility assay we observed a gestationdependent slight decline in the effect of theophylline and rolipram, which suggests that intracellular cAMP accumulation is less appreciable towards the very end of pregnancy. In LPS-treated rats, the maximum effect of theophylline was similar to that in intact 20-day pregnant rats. Contrarily, the effect of rolipram was significantly greater in the LPS-treated rats. Since the inhibition of PDE4 does not affect cAMP production, but maintains high cAMP concentration in the myometrium cells, our results indicate that inflammation probably promotes cAMP generation in the uterus. It corresponds to our previous findings that inflammatory processes in the latepregnant rat uterus potentiate cAMP-related uterine relaxation via elevation of local and systemic TNF- $\alpha$ concentration (Klukovits et al., 2009).

To investigate the extent of cAMP production in the uterus we used forskolin to stimulate the membrane bound adenylyl cyclase. By means of forskolin we could detect intracellular cAMP levels without directly stimulating any membrane receptors (e.g. $\beta$-adrenergic, relaxin, prostaglandin $\mathrm{E} 2$, nociceptin, calcitonin gene-related peptide) which are coupled with stimulatory G-proteins, thus we rather measured the capacity of uterine smooth muscle cells to produce cAMP. We found that in the presence of rolipram the forskolinstimulated cAMP accumulation was higher in the uteri of LPS-treated rats than in those of intact rats. The sensitization of adenylyl cyclase in inflammation was reported recently by our group (Klukovits et al. 2004), corresponding to earlier findings of Osawa et al. (2007).

At the same time, we should note that inflammation may also decrease PDE4 activity in the myometrium, resulting in a slower turnover of CAMP and alter CAMP-mediated relaxation responses. In a recent study, however, no change has been observed in the PDE activity or PDE4B2 expression in the uteri of LPS-challenged pregnant mice (Schmitz et al., 2007). Here we intended to focus on the uterorelaxant effects induced by the combined administration of the $\beta_{2}$-agonist terbutaline with the PDE4 inhibitor rolipram, and also their effect on cAMP accumulation.

The combination of two uterorelaxant drugs may be beneficial to enhance and/or sustain myometrial relaxation. Another advantage of applying a drug combination is to administer lower doses of the individual drugs, which helps to avoid or diminish receptor desensitization. The PDE4-selective rolipram was more effective on the uterus than the non-selective PDE inhibitor theophylline, which 
corresponds to earlier findings on PDE4 transfected cells (Wang et al., 2002). Hence, we chose rolipram to test the possible potentiating effect of PDE4 inhibition on terbutaline-induced uterine relaxation. Rolipram potentiated the relaxing effect of terbutaline by $13 \%$ in the intact rats, and by $25 \%$ in LPS-treated rats. The most pronounced relaxation - 90\% - was detected in the LPS-treated rats, further justifying our hypothesis that cAMP-dependent mechanisms play a major role in the uterus in case of inflammation. Rolipram unequivocally enhanced the terbutaline-induced relaxation, by interfering with the PDE-catalyzed conversion of the biologically active cAMP to $5^{\prime}$-AMP.

We further confirmed the outstanding uterorelaxant effect of the combination of terbutaline with rolipram by measuring the tissue cAMP levels. Terbutaline alone generated a relatively small concentration of cAMP in both animal groups. We note here that measuring tissue cAMP levels without a PDE inhibitor being present is against the conventional method, since cAMP is a rapidly inactivated intracellular signalling molecule. However, we considered that measuring cAMP concentration without a PDE inhibitor is of importance here, to compare the individual versus the combined effect of terbutaline and rolipram on cAMP accumulation. Likewise, we detected a moderate cAMP accumulation in the presence of rolipram alone, without any receptorial stimulation. With the combination of terbutaline and rolipram, however, uterine cAMP levels were much higher, and the highest level was found in the LPS-treated rats.

Our observations are in concordance with previous finding that restraining the breakdown of cAMP with PDE4 inhibitors might act to potentiate the effects of $\beta_{2}$-AR agonists in asthma or COPD, which may in turn result in synergy for inflammatory outcome measures such as exacerbations (Lipworth, 2005). Unfortunately, long-term administration of $\beta_{2}$-AR agonists often leads to reduced therapeutic response due to drug-induced desensitization of $\beta_{2}$-ARs, and their effectiveness is also corrupted by physiological changes in late pregnancy (Gáspár et al., 2005; Giembycz, 1996). It is desirable to test the efficacy of the above drug combination on a long run, before drawing a conclusion related to clinical application. It seems, however, that in case of inflammation, the late-pregnant myometrium reacts with a higher sensitivity to cAMP-dependent relaxation mechanisms. The enhanced responsiveness of the myometrium to $\beta_{2}$-AR stimulation and PDE4 inhibition is probably the consequence of a pathological situation, which might become beneficial as regard to tocolytic therapy.

\section{Conclusion}

In the light of our results, we can conclude that the uterus-relaxing effect of terbutaline was increased notably in the presence of the PDE4 inhibitor rolipram. The combination of terbutaline + rolipram seems favorable to promote myometrium relaxation, especially in the case of genital inflammation, which condition is liable to trigger preterm birth.

Conflict of interest

No conflicts of interest.

\section{Acknowledgement}

This work was supported by the Hungarian OTKA Research Grant (K62707).

\section{References}

Chi ZL, Hayasaka S, Zhang XY, Hayasaka Y, Cui HS, Effects of rolipram, a selective inhibitor of type 4 phosphodiesterase, on lipopolysaccharide-induced uveitis in rats. Investig Ophthalmol Vis Sci 2004;45:2497-502.

de Heus R, Mulder EJ, Derks JB, Visser GH. Acute tocolysis for uterine activity reduction in term labor - a review. Obstet Gynecol Surv 2008;63:383-8.

Dyke HJ, Montana JG. Update on the therapeutic potential of PDE4 inhibitors. Expert Opin Investig Drugs 2002;11:1-13.

Elovitz MA, Mrinalini C. Animal models of preterm birth. Trends Endocrinol Metab 2004:15:479-87.

Farmer P, Pugin J. beta-Adrenergic agonists exert their "anti-inflammatory" effects in monocytic cells through the IkappaB/NF-kappaB pathway. Am J Physiol Lung Cell Mol Physiol 2000;279:L675-82.

Francischi JN, Yokoro CM, Poole S, Tafuri WL, Cunha FQ, Teixeira MM. Antiinflammatory and analgesic effects of the phosphodiesterase 4 inhibitor rolipram in a rat model of arthritis. Eur J Pharmacol 2000;399:243-9.

Giembycz MA. Phosphodiesterase 4 and tolerance to beta 2-adrenoceptor agonists in asthma. Trends Pharmacol Sci 1996;17:331-6.

Gáspár R, Ducza E, Mihályi A, Márki A, Kolarovszki-Sipiczki Z, Páldy E, et al. Pregnancyinduced decrease in the relaxant effect of terbutaline in the late-pregnant rat myometrium: role of G-protein activation and progesterone. Reproduction 2005; 130:113-22.

Gáspár R, Gál A, Gálik M, Ducza E, Minorics R, Kolarovszki-Sipiczki Z, Klukovits A, Falkay G. Different roles of alpha2-adrenoceptor subtypes in non-pregnant and late-pregnant uterine contractility in vitro in the rat. Neurochem Int 2007;51:311-8.

Hatzelmann A, Schudt C. Anti-inflammatory and immunomodulatory potential of the novel PDE4 inhibitor roflumilast in vitro. J Pharmacol Exp Ther 2001:297:267-79.

Houslay A. PDE4 cAMP phosphodiesterases: modular enzymes that orchestrate signalling cross-talk, desensitization and compartmentalization. Biochem J 2003;370:1-18.

Iams JD, Romero R, Culhane JF, Goldenberg RL. Primary, secondary, and tertiary interventions to reduce the morbidity and mortality of preterm birth. Lancet 2008;371:164-75.

Klukovits A, Gaspar R, Santha P, Jancso G, Falkay G. Role of capsaicin-sensitive nerve fibers in uterine contractility in the rat. Biol Reprod 2004;70:184-90.

Klukovits A, Márki A, Páldy E, Benyhe S, Galik M, Falkay G, et al. Inflammatory processes enhance cAMP-mediated uterus relaxation in the pregnant rat: the role of TNF-alpha. Naunyn Schmiedeberg's Arch Pharmacol 2009;379:501-10.

Lindström TM, Bennett PR. The role of nuclear factor kappa B in human labor. Reproduction 2005; 130:569-81.

Lipworth BJ. Phosphodiesterase-4 inhibitors for asthma and chronic obstructive pulmonary disease. Lancet 2005;365:167-75

Lugnier C. Cyclic nucleotide phosphodiesterase (PDE) superfamily: a new target for the development of specific therapeutic agents. Pharmacol Ther 2006;109:366-98.

Méhats C, Schmitz T, Oger S, Hervé R, Cabrol D, Leroy MJ. PDE4 as a target in preterm labour. BMC Pregnancy Childbirth 2007;7(Suppl 1):S12.

Méhats C, Tanguy G, Dallot E, Robert B, Rebourcet R, Ferre F, et al. Selective up-regulation of phosphodiesterase-4 cyclic adenosine 3', 5'-monophosphate (cAMP)-specific phosphodiesterase variants by elevated cAMP content in human myometrial cells in culture. Endocrinology 1999; 140:3228-37.

Oger S, Méhats C, Dallot E, Cabrol D, Leroy MJ. Evidence for a role of phosphodiesterase 4 in lipopolysaccharide-stimulated prostaglandin E2 production and matrix metalloproteinase-9 activity in human amniochorionic membranes. J Immunol 2005; 174:8082-9.

Osawa Y, Yim PD, Xu D, Panettieri RA, Emala CW. Raf-1 kinase mediates adenylyl cyclase sensitization by TNF-alpha in human airway smooth muscle cells. Am J Physiol Lung Cell Mol Physiol 2007;292:L1414-1421.

Romero R, Mazor M, Wu Y, Sirtori M, Oyarzun E, Mitchell MD, et al. Infection in the pathogenesis of preterm labor. Semin Perinatol 1988;12:262-79.

Schmitz T, Souil E, Hervé R, Nicco C, Batteux F, Germain G, et al. PDE4 inhibition prevents preterm delivery induced by an intrauterine inflammation. J Immunol 2007; $178: 1115-21$

Wang P, Wu P, Ohleth KM, Egan RW, Billah MM. Phosphodiesterase 4B2 is the predominant phosphodiesterase species and undergoes differential regulation of gene expression in human monocytes and neutrophils. Mol Pharmacol 1999;56: $170-4$

Wang K, Chen JQ, Chen Z, Chen JC. Inhibition of human phosphodiesterase 4A expressed in yeast cell GL62 by theophylline, rolipram, and acetamide- 45 . Acta Pharmacol Sin 2002;23:1013-7.

Withworth M, Quenby S. Prophylactic oral betamimetics for preventing preterm labour in singleton pregnancies. Cochrane Database Syst Rev 2008;23 CD006395. 